Indian Journal of Science and Technology

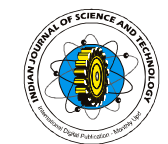

\title{
Studies on the effect of ethanol addition to biodiesel: Performance and emissions of a diesel engine
}

\author{
M. Pugazhvadivu \\ Department of Mechanical Engineering, Pondicherry Engineering College, Puducherry-605 014, India \\ pv_pec@yahoo.com
}

\begin{abstract}
The interest on alternative fuels is continuously increasing to meet the growing energy needs and protect the environment. Ethanol and biodiesel are two potential and promising alternative fuels for internal combustion engines. Ethanol can be used with biodiesel fuel to extent the availability of diesel. In this work, experimental investigations were carried on a single cylinder diesel engine using B25, B50, B75 and B100 biodiesel diesel blends with $5 \%$ and $10 \%$ ethanol addition. The engine performance and emission characteristics were investigated. The thermal efficiency, $\mathrm{NO}_{x}$ and smoke emissions were found experimentally. The addition of ethanol to biodiesel diesel blends did not alter the engine performance significantly. The engine produced lower $\mathrm{NO}_{x}$ and smoke emission with ethanol addition.
\end{abstract}

Keywords: Biodiesel, ethanol, emission, alternate fuel.

Introduction

Biodiesel has properties similar to diesel and therefore can be used in diesel engines with less or no engine modifications. Biodiesel is non-toxic, biodegradable and contains no aromatics and sulfur. It can be blended with diesel at any proportion. Engine efficiency with biodiesel is proved to be comparable with diesel (Kalligeros et al., 2003). Biodiesel also provides considerable emission benefits such as reduced smoke, carbon-monoxide (CO) and unburnt hydrocarbon $(\mathrm{HC})$. Wang et al. (2000) tested nine heavy duty trucks fuelled with B35 and noted reduction in particulate matter (PM) and HC. Venteswararao et al. (2008) tested different blends of biodiesel produced from pongamia, jatropha and neem oil.

The biodiesel diesel blends have been reported to produce lower smoke, $\mathrm{CO}$ and $\mathrm{HC}$ and higher oxides of nitrogen (NOX). Serdari et al. (2000) conducted emission tests using sunflower, corn, olive and used frying oil biodiesel and its blends with diesel. The test results indicated increase in $\mathrm{NO}_{x}$ emission and significant decrease in PM. Nabi et al., (2006) investigated the exhaust emissions of a diesel engine using neem biodiesel and its blends with diesel. They found lower $\mathrm{CO}$ and smoke emissions but higher NOx emission.

Ethanol is a renewable fuel which offers excellent performance and reduced air pollution compared to conventional petroleum fuels. The use of ethanol diesel blends is one of the strategies to extend the availability of diesel. However, ethanol and diesel are immiscible and the

\begin{tabular}{|l|c|c|c|c|c|c|c|}
\hline Table 1. Properties of fuels \\
\hline Property & B50 & B50E5 & B50E 10 & B100 & B100E5 & B100E 10 & Diesel \\
\hline $\begin{array}{c}\text { Viscosity } \\
\text { @ } 40^{\circ} \mathrm{C}(\mathrm{cSt})\end{array}$ & 3.56 & 3.45 & 3.23 & 5.82 & 5.00 & 4.82 & 3.0 \\
\hline Flash point ${ }^{\circ} \mathrm{C}$ & 84 & 53 & 41 & 160 & 81 & 75 & 70 \\
\hline
\end{tabular}


that of diesel. In addition, the viscosity of $\mathrm{B} 100$ and $\mathrm{B} 50$ reduced with ethanol addition, due to the fact that ethanol has lower density and viscosity compared to B100 and B50. The flash point of B100 and B50 fuels are higher than diesel. The flash point of B100 and B50 fuels reduce drastically with ethanol addition due to the very low flash point of ethanol $\left(13^{\circ} \mathrm{C}\right)$.

The experiments were carried out in a stationary diesel engine (Kirloskar make) coupled to an alternator and a loading rheostat. The fuel consumption and emission measurements were taken at different engine loads. The experimental setup is shown in Fig 1. The engine specification is presented in Table 2. The $\mathrm{NO}_{\mathrm{X}}$

Fig. 1 Experimental setup

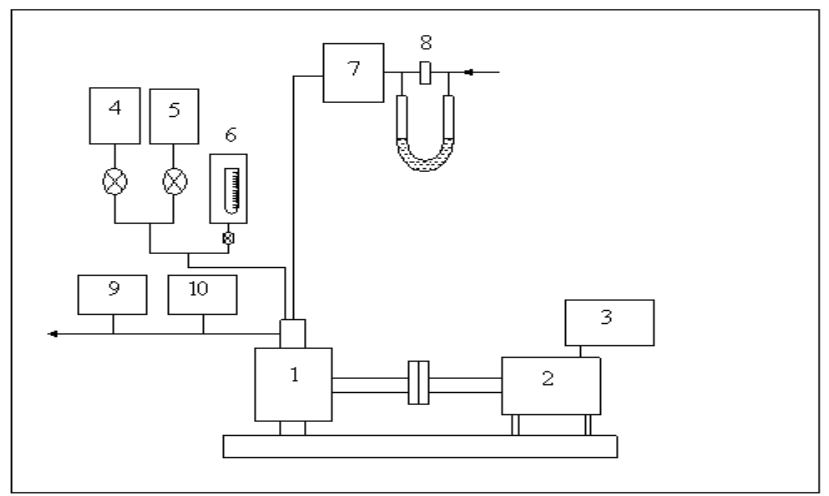

1. Diesel engine; 2. Electrical generator;

3. Electrical load box; 4. Diesel fuel tank;

5. Biodiesel fuel tank; 6. Burette; 7. Surge tank;

8. Orifice plate; 9. NOx analyzer;

10. Smoke analyzer

concentration in the exhaust gas was measured using NOx analyzer with chemical sensor (Technovation make). The smoke density was measured using AVL smoke meter.

\section{Results and discussion}

Based on experimental data, the graphs were drawn for the variations in brake thermal efficiency, $\mathrm{NO}_{x}$ and smoke emission with respect to brake power. The variation of brake thermal efficiency at various power outputs of the engine is compared between diesel, B100 and B50 in Fig.1a. The brake thermal efficiency has a tendency to increase with increase in load for all the fuels. This is due to the reduction in heat loss and increase in power developed with increase in load. It is seen that the brake thermal efficiency of the engine with B100 and B50 is lower than diesel at all loads. The lower heat content and higher density of biodiesel fuels resulted in lower thermal efficiency. Fig.1b and Fig.1c shows the variation of brake thermal efficiency with respect to brake power with ethanol addition to $\mathrm{B} 100$ and $\mathrm{B} 50$ respectively. The
Vol.2 No. 11 (Nov. 2009)

ISSN: 0974- 6846

brake thermal efficiency for both $\mathrm{B} 100$ and B50 is found to decrease marginally with ethanol addition due to the presence of oxygen and low heat content of ethanol.

\section{$\mathrm{NO} \times$ emission}

The variation of $\mathrm{NO}_{x}$ emission at various power outputs for B50 and B100 fuels is shown in Fig 2a. Compared to Fig. 1a. Thermal efficiency

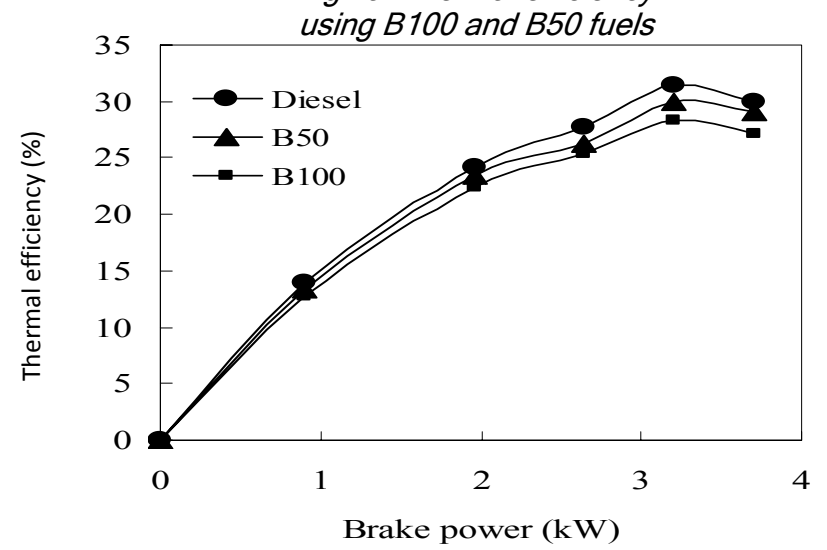

Fig. 1b. Effect of ethanol addition
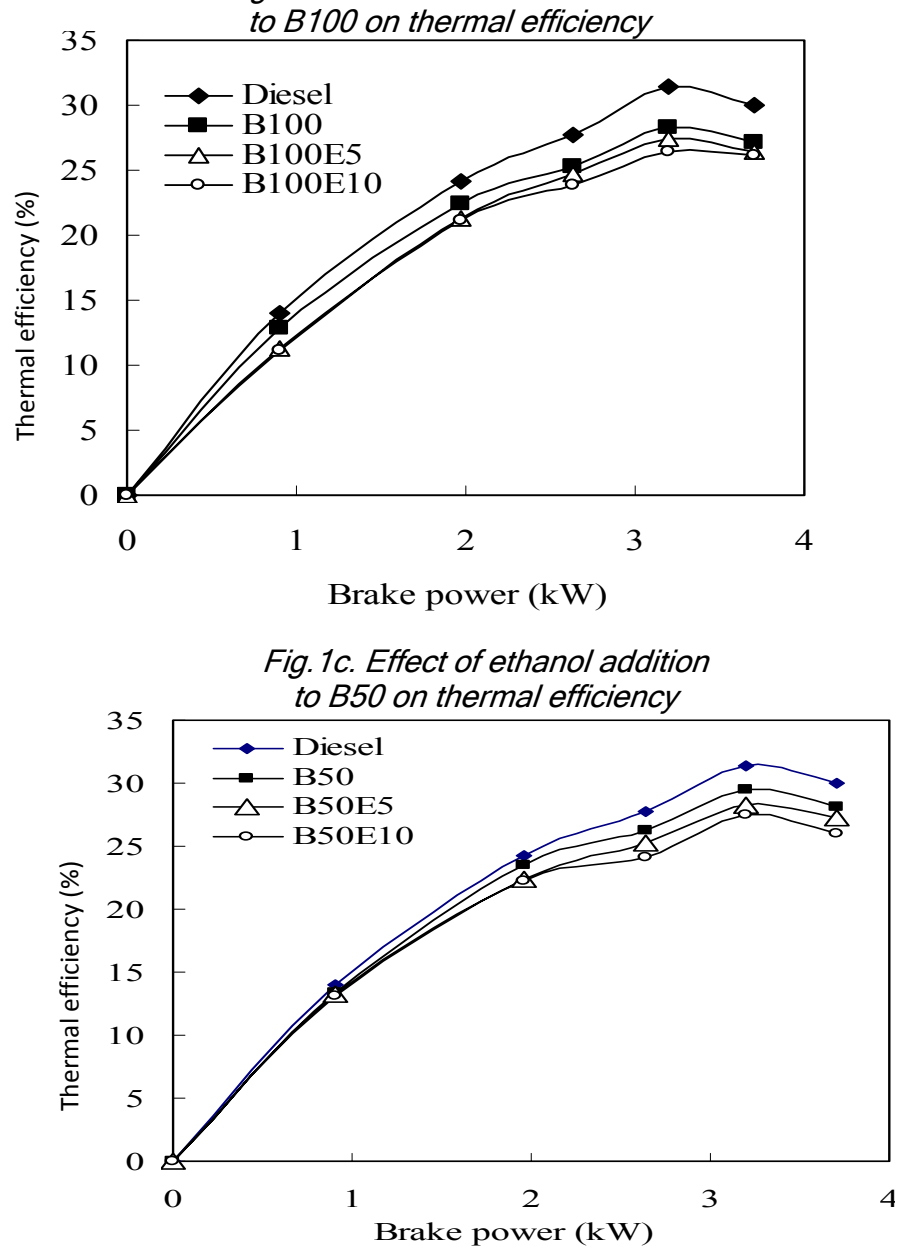

Pugazhvadivu Indian J.Sci.Technol. 
Fig. 2a. NOx emission using $B 100$ and $B 50$ fuels

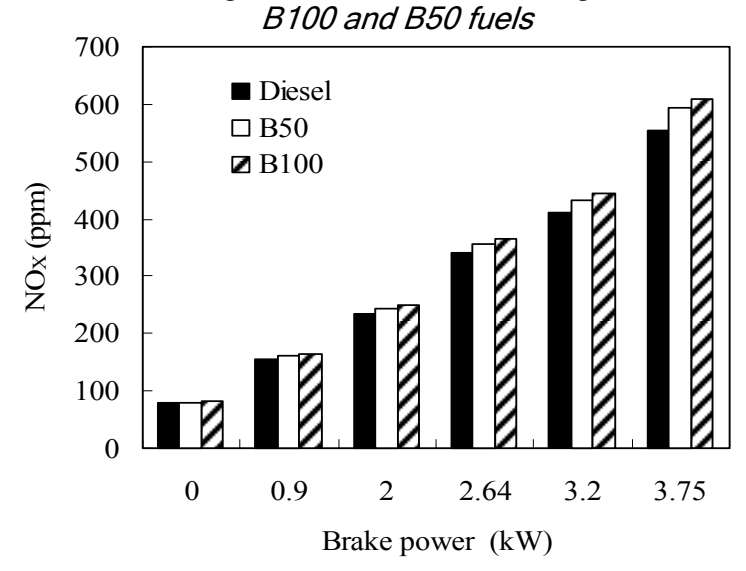

Fig.2b. Effect of ethanol addition to $B 100$ on NOx emission

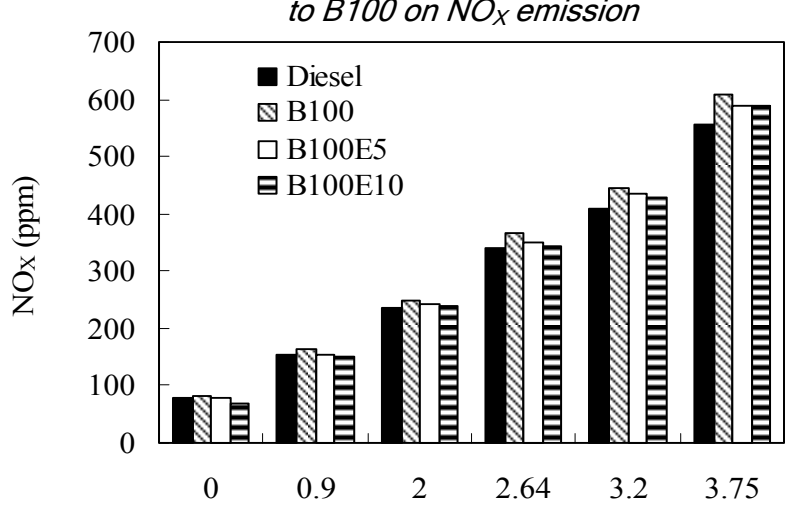

Brake power $(\mathrm{kW})$

Fig.2c. Effect of ethanol addition to $B 50$ on $N O_{x}$ emission

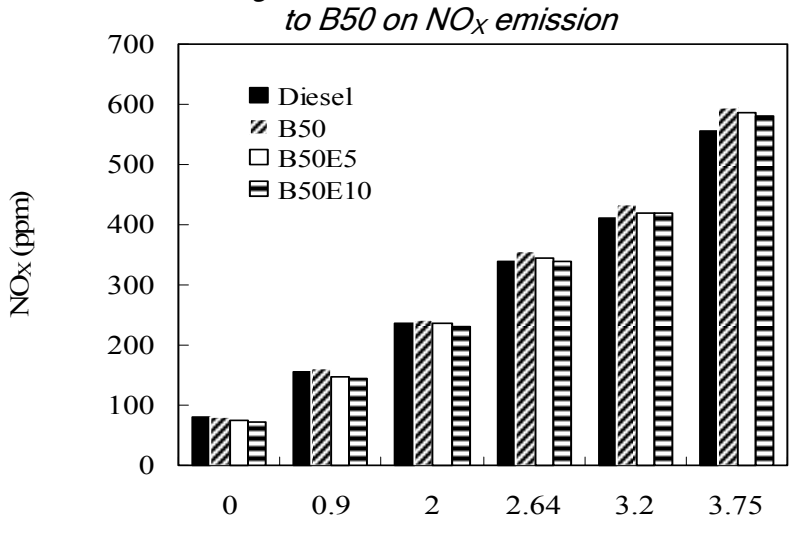

Brake power $(\mathrm{kW})$

diesel, the $\mathrm{NO}_{x}$ emission using $\mathrm{B} 50$ and $\mathrm{B} 100$ fuels are higher. The increase in $\mathrm{NO}_{x}$ emission may be due to the oxygen present in biodiesel, which is added to fuel rich zones, resulting in the oxidation of nitrogen (Serdari et al., 2000, Nabi et al., 2006). Szybist et al. (2005) showed that the higher bulk modulus for biodiesel fuels produce an advance in injection timing compared to diesel fuel which causes an increase in $\mathrm{NO}_{x}$ emissions. At maximum power output, the $\mathrm{NO}_{x}$ emission increased by $10 \%$ and $7 \%$ with $\mathrm{B} 100$ and $\mathrm{B} 50$ respectively.

Fig. $2 b$ and Fig. 2c show the variation of $\mathrm{NO}_{x}$ emission at various power outputs with $5 \%$ and $10 \%$ ethanol added to B100 and B50 respectively. The $\mathrm{NO}_{\mathrm{X}}$ emission is found to decrease with ethanol addition. As ethanol contains oxygen it can be thought of adding oxygen in the same way as biodiesel. However, for ethanol other factors such as heat of evaporation and flame temperature also dominate. Ethanol has a higher heat of evaporation and reduces the combustion temperature. Ren et al. (2008) showed that the temperature drop due to the high heat of evaporation of ethanol reduce $\mathrm{NO}_{x}$ emission. The flame temperature of ethanol is $1930^{\circ} \mathrm{C}$ whereas it is $2054^{\circ} \mathrm{C}$ for diesel fuel (Wyman, 1996). The lower flame temperature of ethanol may be another reason for the reduction in $\mathrm{NO}_{x}$ emission. At lower power outputs, the decrease in $\mathrm{NO}_{x}$ emission is higher. This is due to the fact that the large heat of evaporation of ethanol results in high temperature reduction at lower load and the in-cylinder temperature at the end of compression stroke is very low compared to high loads. There is only a marginal decrease in $\mathrm{NO}_{x}$ emission at higher power outputs.

\section{Smoke emission}

The smoke emission with B100 and B50 is shown in Fig.3a. The smoke emission was higher at high loads since the air-fuel ratio decreases with increase in load (Ramadhas, 2005). It is seen that B100 and B50 emit lower smoke compared to diesel due to the presence of oxygen in these fuels. The smoke emission with B100 was lower compared to B50 as B100 contains more oxygen than B50. Compared to diesel, the maximum smoke density with B100 and B50 are $25 \%$ and $16 \%$ lower respectively. Fig.3a and Fig. $3 \mathrm{~b}$ show the effect of ethanol addition to B100 and B50 on smoke density. The results clearly show that the exhaust smoke could be decreased markedly on the addition of ethanol to diesel fuel. The addition of ethanol decreases the engine smoke by providing more oxygen and making it burn completely.

\section{Conclusion}

The addition of ethanol to B100 and B50, fuels produced from pongamia oil resulted in a marginal decrease in engine thermal efficiency. Compared to B100 and $\mathrm{B} 50$, the $\mathrm{NO}_{x}$ emission decreased at low and medium power outputs significantly. At rated power output, the $\mathrm{NO}_{x}$ emission decreased marginally. The smoke emission was lower for B100 and B50 fuels. The addition of ethanol to $\mathrm{B} 100$ and $\mathrm{B} 50$ resulted in significant decrease in smoke emission compared to diesel. It is thus possible to achieve simultaneous reduction of $\mathrm{NO}_{\mathrm{X}}$ and smoke emission by adding ethanol to B100 and B50. It is concluded that the addition of $5 \%$ to $10 \%$ ethanol with 
biodiesel fuels can extend the availability of diesel and reduce the $\mathrm{NO}_{x}$ and smoke emissions simultaneously.

\section{Acknowledgement}

The authors acknowledge the financial assistance provided by the DST, Govt. of India.

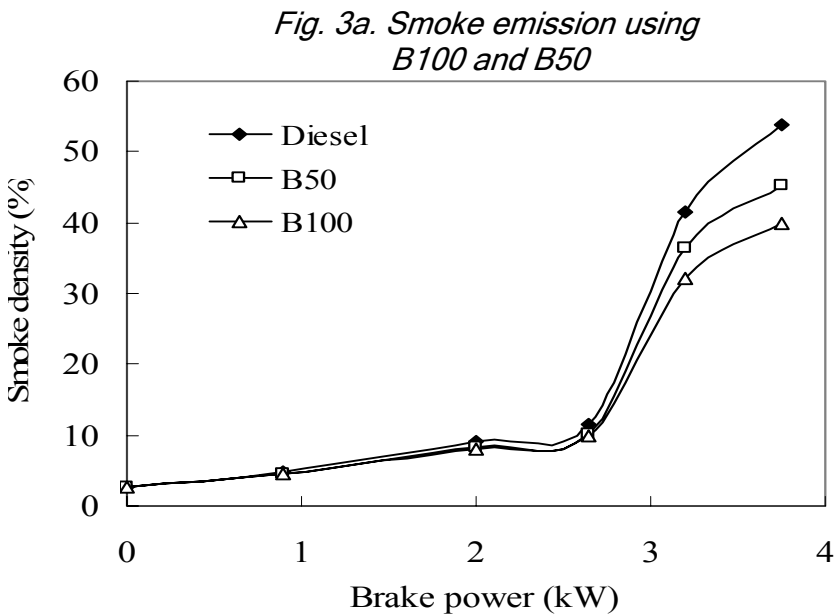

Fig. 3b. Effect of adding ethanol to $B 100$ on smoke density

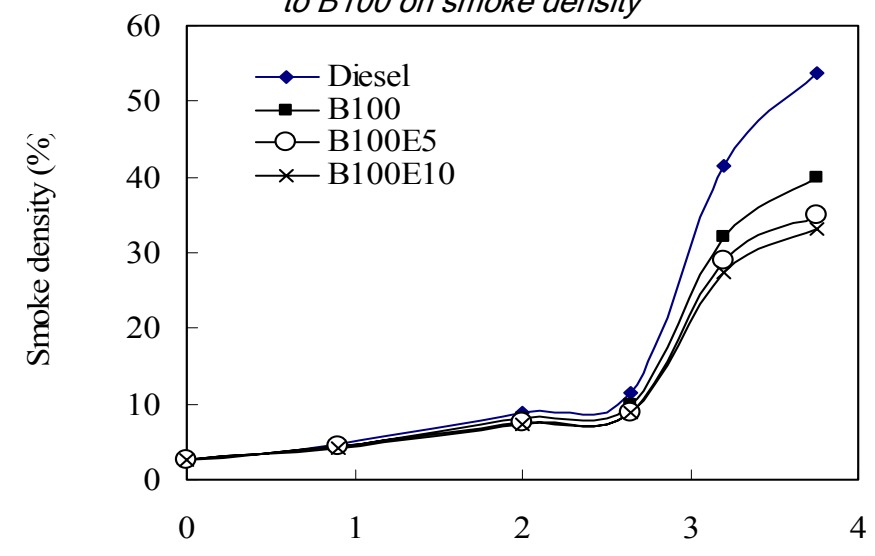

Brake power $(\mathrm{kW})$

Fig.3c. Effect of adding ethanol

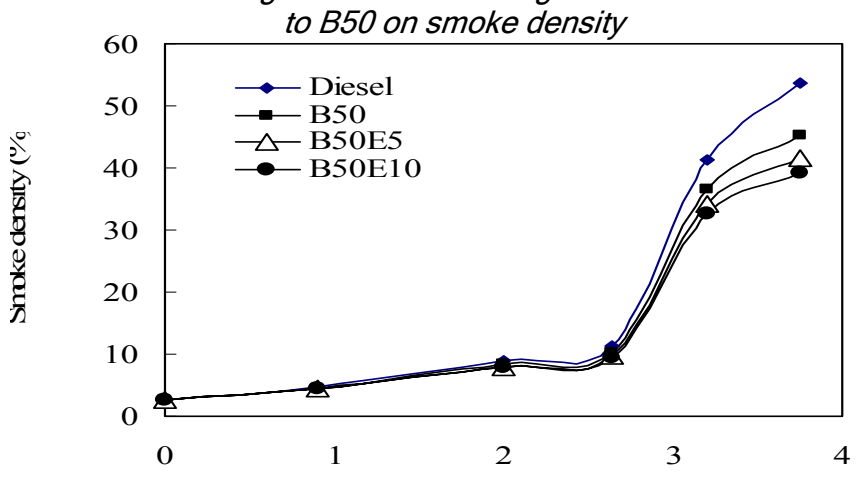

Vol.2 No. 11 (Nov. 2009)

ISSN: 0974- 6846

\section{References}

1. Barnwal BK and Sharma MP (2005) Prospects of biodiesel production from vegetable oils in India. $J$. Renew. \& Sust. Energ. Rev. 9, 363-378.

2. Hansen AC, Peter QZ and Lyne WL (2005) Ethanoldiesel fuel blends-a review. Biores. Tech. 96, 277 285.

3. Kalligeros S, Zannikos F, Stournas S, Lois E, Anastopoulos G, Teas $\mathrm{CH}$ and Sakellaropoulos F (2003) An investigation of using biodiesel/marine diesel blends on the performance of a stationary diesel engine. Biomas. \& Bioenerg. 24, 141-149.

4. Kwanchareon $P$, Luengnaruemitchai $A$ and Jai-In S (2007) Solubility of a diesel-biodiesel-ethanol blend, its fuel properties and its emission characteristics from diesel engine. Fuel. 86, 1053-1061.

5. Nabi MN, Akhter MS and Shahadat MMZ (2006) Improvement of engine emissions with conventiona diesel fuel and diesel-biodiesel blends. Biores. Tech. 97, 372-378.

6. Patil PD and Shuguang Deng (2009) Optimization of biodiesel production from edible and non-edible vegetable oils. Fuel. 88, 1302-1306.

7. Ramadhas AS, Muraleedharan $C$ and Jayaraj S (2005) Performance and emission evaluation of a diesel engine fuelled with methyl esters of rubber seed oil. Renewable Energy. 30, 1789-1800

8. Ren Y, Huang Z-H, Jiang D-M, Li W, Liu B and Wang $X-B$ (2008) Effect of the addition of ethanol and cetane number improver on the combustion and emission characteristics of a compression ignition engine. Proc. IMechE. Part D: J. Autom. Engg. 222, 1077-1087.

9. Serdari A, Fragioudakis K, Kalligeros S, Stournas S and Lois E (2000) Impact of using biodiesel of different origin and additives on the performance of a stationary diesel engine. J. Engg. gas turb. \& pow. 122, 624-631.

10. Szybist JP, Boehman AL, Taylor JD and McCormick $\mathrm{RL}$ (2005) Evaluation of formulation strategies to eliminate the biodiesel $\mathrm{NO}_{x}$ effect. Fuel Process. Tech. 86, 1109- 1126.

11. Venketeswararao $T$, Prabhakararao $G$ and Hemachandra Reddy K (2008) Experimental investigation of pongamia, jatropha and neem methyl esters as biodiesel on C.I. engine. Jordan J. Mech \& Indus Engg. 2, No 2, 117-122.

12. Wang WG, Lyons DW, Clark NN, Gautham M and Nortan PM (2000) Emissions from nine heavy duty trucks fuelled by diesel and biodiesel blend without engine modification. Envi. Sci. \& Tech. 34, 933-939.

13. Wyman CE (1996) Handbook on bioethanol: Production and utilization, Taylor \& Francis, Washington DC.

Brake power $(\mathrm{kW})$

Research article

CIndian Society for Education and Environment (iSee)
"Biodiesel"

http://www.indjst.org
Pugazhvadivu Indian J.Sci.Technol. 